\title{
Application of Near-infrared Spectroscopy to Quantify Fat and Total Solid Contents of Sweetened Condensed Creamer
}

\author{
S. Subajiny, M.M. Jayasiri ${ }^{1}$ and Terrence Madhujith ${ }^{2 *}$ \\ Postgraduate Institute of Agriculture \\ University of Peradeniya \\ Sri Lanka
}

\begin{abstract}
Near-infrared (NIR) spectroscopy has emerged in food industry as a rapid, non-destructive method in the quality analysis of food and beverages. The objective of the present study was to explore the applicability of NIR spectroscopy for rapid quantification of fat and total solid content of a dairy product, sweetened condensed creamer. Samples (30 for fat and 24 for total solids) were analyzed using NIR spectroscopy and standard methods. Opus spectroscopy software was used to develop calibration models for the components examined. The calibration models were prepared using spectra obtained for both fat and total solid content. The constructed calibration models were validated by cross validation. The correlation coefficients $\left(R^{2}\right)$ between the values obtained from two methods were determined. The values obtained for fat and total solid contents by NIR spectroscopy and standard method were not significantly different $(p>0.05)$. The $R^{2}$ values determined for calibration were, 0.91 for fat and 0.87 for total solids while $R^{2}$ values for validation were 0.96 for fat and 0.96 for total solids. The results of the present study showed a strong relationship between results obtained by NIR spectroscopy and respective standard methods. Thus, it can be concluded that NIR spectroscopy is applicable for a routine analysis of fat and total solid content of Sweetened Condensed Creamer.
\end{abstract}

Keywords: Fat, near infra-red (NIR) spectroscopy, sweetened condensed creamer, total solid

\section{INTRODUCTION}

Trends in analytical chemistry are towards simple and less time consuming analytical methods. Infrared spectroscopy is a technique that has been proposed as an excellent alternative to traditional methods for quality analysis of food and beverages (Shiroma and Rodriguez-Saona, 2009). Near-infrared (NIR) spectroscopy is based on the absorption of electromagnetic radiation at wavelengths in the range of 780-2500 nm. NIR spectra of foods comprise of broad bands arising from overlapping absorptions corresponding mainly to overtones and combinations of vibrational modes involving $\mathrm{C}-\mathrm{H}, \mathrm{O}-\mathrm{H}$ and $\mathrm{N}-\mathrm{H}$ chemical bonds (Osborne, 2006).

The NIR spectroscopy possesses multiple characteristics such as rapidity, simplicity, cost effectiveness, potential for routine analysis if proper calibration and validation is developed, and non-requirement of special skilled operator among others (Shiroma and RodriguezSaona, 2009). In addition, for each fundamental vibration there exists a corresponding series

\footnotetext{
Silver Mills Limited, Loluwagoda, Meerigama

Department of Food Science and Technology, Faculty of Agriculture, University of Peradeniya, Sri Lanka

*. Corresponding author: madujith@yahoo.com
} 
of overtone and combination bands with each successive overtone band approximately an order of magnitude less intense than the preceding one. This provides a built-in dilution series which allows several choices of absorptions of different intensity containing the same chemical information. Further, the relatively weak absorption due to water enables highmoisture foods to be analyzed (Osborne, 2006). It is mainly used to determine fat or oil, protein and moisture levels of food products, serving a grading and quality assurance function.

Sweetened condensed creamer is a smooth viscous liquid manufactured from fresh milk, which is then standardised, mixed with sugar and pasteurised before evaporating. It is used undiluted in tea, coffee or cocoa and also ideal to be used in various recipes as a sweet topping on desserts, bakery products and fresh fruit. According to Food and Drug Administration (FDA), minimum requirement for analysis of sweetened condensed full cream include the analysis of Total Milk Solids (28\% minimum) and Milk Fat $(8.5 \%$ minimum) (FDA, 2013). The traditional methods for determining the quality of milk products and its major components are slow and expensive (Jankovska and Sustova, 2003). Therefore this study aimed to explore the applicability of NIR spectroscopy for quantifying fat and total solid content of sweetened condensed creamer.

\section{METHODOLOGY}

The sweetened condensed creamer samples were obtained from Nestle Lanka PLC, Pannala, Sri Lanka. Ammonia solution, ethyl alcohol, diethyl ether, petroleum ether and Congo red indicator were obtained from Analytical Instruments Limited, Sri Lanka. All the chemicals were of analytical grade.

\section{Sample preparation}

The number of samples selected for fat and total solid contents were 30 and 24, respectively. The calibration samples were selected to represent a range of concentrations that represents the actual fat and total solid contents (fat content ranged from $12.0 \%$ to $14.0 \%$ and total solid content ranged from $72.0 \%$ to $75.0 \%$ ). The samples were gently mixed by repeatedly inverting the package before samples were drawn for analysis. After opening the package, the samples were mixed well again with a spatula.

\section{Analysis of samples using FT-NIR analyzer}

First, instrument check tests were performed. Two test portions were taken from the same sample within the shortest feasible time interval ( $<5 \mathrm{~min}$.). Analyses were carried out in duplicates. Then each sample was fed to the FT-NIR Analyzer (Bruker multipurpose analyzer) to analyze fat and total solid content.

The calibration models were created by Opus/Spectroscopy Software (version 6-QUANT). Samples were analyzed for calibration and cross validation of the calibration performed. The calibration models were prepared by using spectra which have been measured. 


\section{Determination of fat content by Mojonnier method}

Total fat contents of the samples were determined using Mojonnier method as described by Min and Ellefson (2010). The first extraction was performed using ether while the second extraction was performed using ethyl alcohol, diethyl ether and petroleum ether. Third extraction was done using diethyl ether and petroleum ether. Blank test was also performed. The fat content was calculated as shown in Equation 1.

Fat content $(\%)=[\{(\mathrm{Wt}$ of dish + residue $)-(\mathrm{Wt}$ of dish $)\}-\mathrm{Wt}$ of blank residue $] \times 100$ Wt of sample

where, Wt- weight $(\mathrm{g})$

\section{Analysis of total solid content using a standard method}

Total solids were determined by drying a known mass of milk at $102 \pm 1{ }^{\circ} \mathrm{C}$ for 4 hours and subsequent weighing to determine the mass loss (Cvak et al., 1992). The total solid content was calculated as shown in Equation 2.

Total solid content $(\%)=\underline{(\mathrm{Wt} \text { of dish }+ \text { residue })-(\mathrm{Wt} \text { of dish })} \times 100$

$$
\text { Wt of sample }
$$

where, Wt- weight $(\mathrm{g})$

\section{Statistical analysis}

The data were analyzed using Minitab 16 and Microsoft (Excel) procedures. The results of the standard methods and NIR spectroscopy were statistically analyzed using paired t-test test in MINITAB. Correlations among data obtained were calculated using Pearson's correlation coefficient $(\mathrm{R})$.

\section{RESULTS AND DISCUSSION}

\section{Comparison of standard method and NIR spectroscopy}

The results of the statistical analysis of values for fat and total solid content obtained by NIR spectroscopy and standard methods by paired-t-test using MINITAB 16 are summarized in Table 1. There are no significant differences $(p>0.05)$ between the values obtained for fat and total solid contents by both methods.

Table 1. Results of analysis by paired-t-test using MINITAB $(p=0.05)$

\begin{tabular}{lccclclll}
\hline Component & $\mathbf{n}$ & $\mathbf{x}-\mathbf{N I R}$ & $\mathbf{x}-$ Std & D mean & SD & p-value & SE mean & T-value \\
\hline Fat & 30 & 12.469 & 12.458 & -0.011 & 0.107 & 0.589 & 0.0195 & -0.55 \\
Total solid & 24 & 73.325 & 73.376 & 0.051 & 0.170 & 0.158 & 0.0347 & 1.46 \\
\hline
\end{tabular}

$\mathrm{n}$ - Number of samples; $\mathrm{x}$-NIR- Average of NIR values; $\mathrm{x}$ - Std- Average of standard values; $\mathrm{d}$ mean- difference between average standard and NIR values; SD - Standard deviation of the 
mean difference; p-value- probability value at $95 \%$ confidence interval, Se-mean- Standard error of mean difference

\section{Chemometric models and their validation}

The purpose of developing chemometric models and their validation is the quantitative analysis of an unknown multi component sample. Chemometric models were developed separately for fat and total solid content using calibration samples of known composition that are representative for the system. The NIR spectra of these samples were used to calculate a calibration function, which essentially is the model used for the analysis of unknown samples later. However, the model was validated by cross validation to test its reliability of prediction.

Samples for calibration were selected in a way that they cover a wider concentration range than intend to analyze later. This helps create a more stable model for analysis. This becomes increasingly important when there are outliers, with concentrations that largely deviate from desired values, as this maybe the case in quality control.

\section{Setting up a chemometric model and its validation for fat and total solid content}

The determined correlation coefficients for calibration were for fat 0.911 and total solids 0.870 , and the correlation coefficients for validation found were for fat 0.968 and total solids 0.960 (Figures 1-4). Differences between the values obtained by NIR spectroscopy and standard method for both fat and total solid content were not significant $(\mathrm{p}>0.05)$.

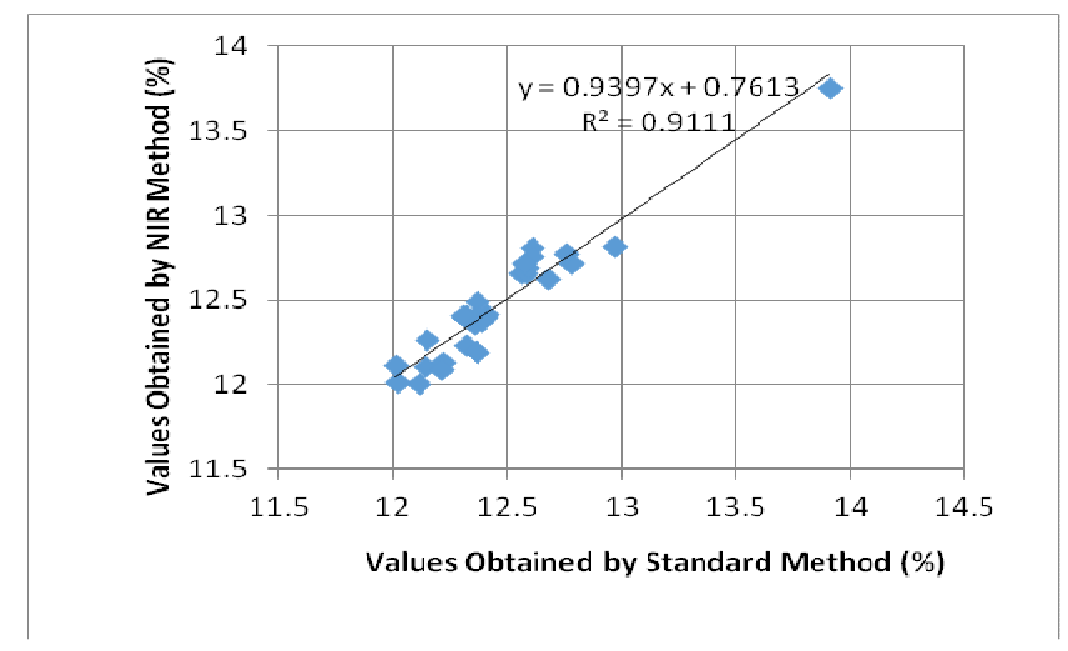

Fig. 1. Correlation between the values of fat content obtained by NIR spectroscopy and standard method 


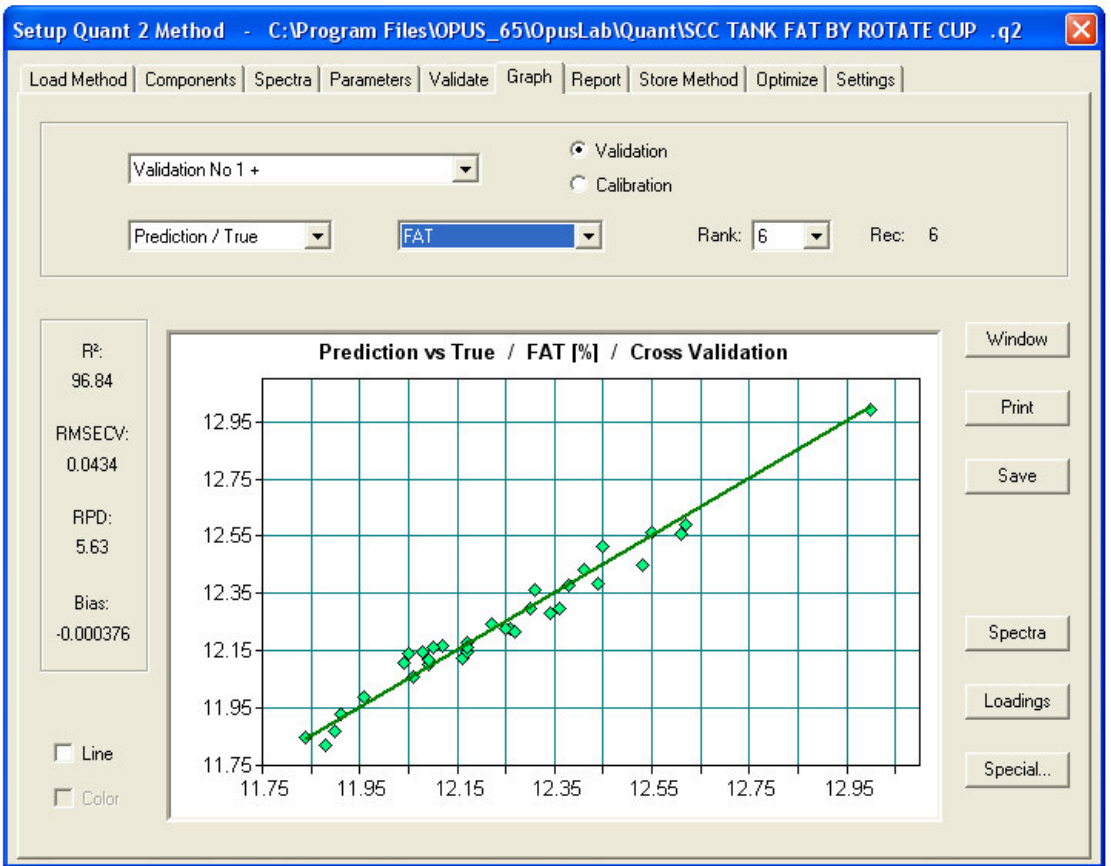

Fig. 2. Window which displays the correlation between the prediction values and Setting up a chemometric model for total solid content and its validation

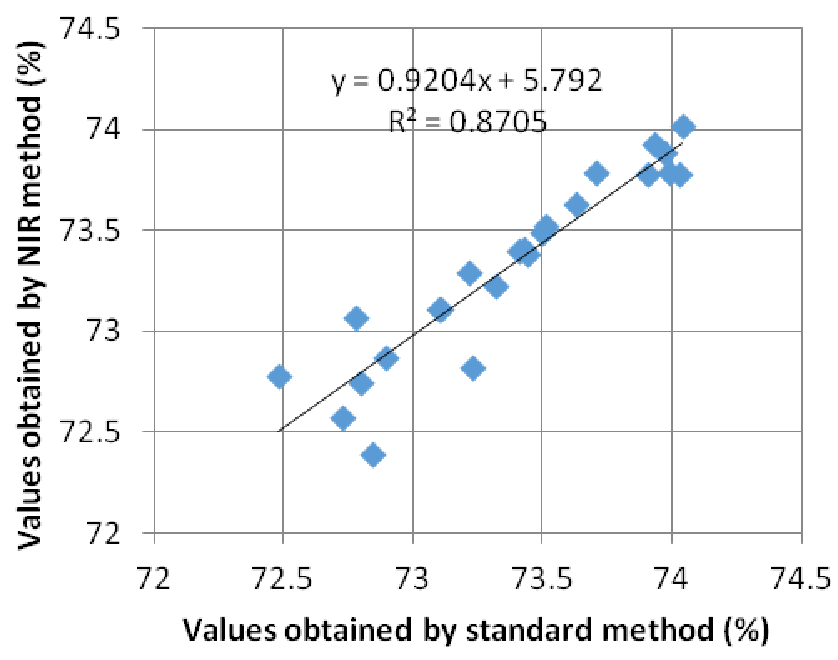

Fig. 3. Correlation between the values of total solid content obtained by NIR spectroscopy and standard method 


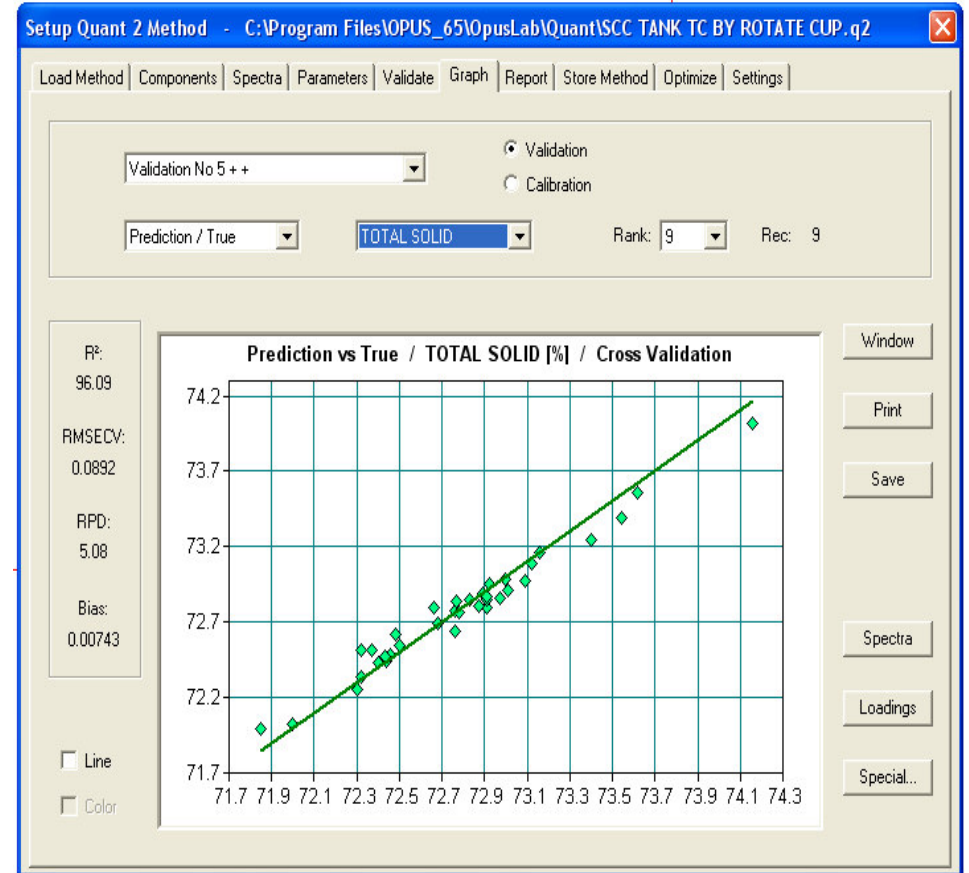

Fig. 4. Window which displays the correlation between the prediction values and values obtained by standard method for total solid content

\section{CONCLUSION}

The study revealed that fat and TS content of sweetened condensed creamer measured by NIR have a strong correlation with the values obtained by standard methods. The cross validation indicated the possibility of the use of NIR spectroscopy for the determination of fat and total solid content of sweetened condensed creamer. Therefore it can be concluded that NIR spectroscopy can be applied for routine analysis of fat and total solid content of sweetened condensed creamer and related products.

\section{REFERENCES}

Cvak, Z., Peterkova, L. and Černa, E. (1992). Chemical and physic-chemical methods in milk and dairy product quality control. Praha: VUP, Milcom servis a.s. Praha. 12-13. ISBN 80-85120-36-4.

FDA. (2013). Minimum requirement for analysis of finished product. Annex J: Summary of current food standards as of 04 April 2013 [on line]. [Accessed on 4.07.2014]. Available at http://www.fda.gov.ph/attachments/article/71149/Annex\%20J\%20\%20FOOD\%20STANDARDS.pdf 
Jankovska, R. and Sustova, K. (2003). Analysis of cow milk by near-infrared spectroscopy. Czech J. Food Sci., 21, 123 - 128.

Min, D.B. and Ellefson, W.C. (2010). Fat analysis. pp 117-132. In: Nielson, S.S. (Ed.) Food Analysis, $4^{\text {th }}$ edition, Springer US.

Osborne, B.G. (2006). Near-Infrared Spectroscopy in Food Analysis. In: Encyclopedia of Analytical Chemistry [on line]. [Accessed on 03.07.2014]. Available at http://onlinelibrary.wiley.com/doi/10.1002/9780470027318.a1018/abstract

Shiroma, C. and Rodriguez-Saona, L. (2009). Application of NIR and MIR spectroscopy in quality control of potato chips. Journal of Food Composition and Analysis, 22, 596 - 605. 